University of Nebraska - Lincoln

DigitalCommons@University of Nebraska - Lincoln

Agronomy \& Horticulture -- Faculty Publications

Agronomy and Horticulture Department

$11-1991$

\title{
Describing and Quantifying Growth Stages of Perennial Forage Grasses
}

\author{
K. J. Moore \\ University of Nebraska-Lincoln \\ Lowell E. Moser \\ University of Nebraska-Lincoln, Imoser1@unl.edu \\ Kenneth P. Vogel \\ University of Nebraska-Lincoln, kvogel1@unl.edu \\ Steven S. Waller \\ University of Nebraska-Lincoln, swaller1@unl.edu \\ B. E. Johnson \\ University of Nebraska-Lincoln
}

See next page for additional authors

Follow this and additional works at: https://digitalcommons.unl.edu/agronomyfacpub

Part of the Plant Sciences Commons

Moore, K. J.; Moser, Lowell E.; Vogel, Kenneth P.; Waller, Steven S.; Johnson, B. E.; and Pedersen, Jeffrey F., "Describing and Quantifying Growth Stages of Perennial Forage Grasses" (1991). Agronomy \& Horticulture -- Faculty Publications. 507.

https://digitalcommons.unl.edu/agronomyfacpub/507

This Article is brought to you for free and open access by the Agronomy and Horticulture Department at DigitalCommons@University of Nebraska - Lincoln. It has been accepted for inclusion in Agronomy \& Horticulture -Faculty Publications by an authorized administrator of DigitalCommons@University of Nebraska - Lincoln. 


\section{Authors}

K. J. Moore, Lowell E. Moser, Kenneth P. Vogel, Steven S. Waller, B. E. Johnson, and Jeffrey F. Pedersen 


\section{DESCRIBING AND QUANTIFYING GROWTH STAGES OF PERENNIAL FORAGE GRASSES}

\author{
K. J. MoOre,* L. E. Moser, K. P. Vogel, S. S. WALler, \\ B. E. JOHNSON, AND J. F. PEDERSEN
}

\begin{abstract}
A system for identifying and quantifying the stages of growth and development of perennial forage grasses was developed. The system consists of a universal set of morphological descriptors for forage and range grasses and a continuous numerical index. The life cycle of individual grass tillers is divided into five primary growth stages (i) germination, (ii) vegetative, (iii) elongation, (iv) reproductive, and (v) seed ripening. Substages corresponding to specific morphological events are defined within each primary stage. Each growth stage consists of a primary and secondary stage and has both a mnemonic code and numerical index associated with it. The codes were designed to be easily memorized and are useful for applying the system in the field. The numerical index is included so that the stages can be expressed quantitatively.
\end{abstract}

\begin{abstract}
$\mathrm{A}$ CCURATE IDENTIFICATION of the growth stage of a grass population is critical to many forage management decisions. Production practices involving establishment, grazing management, harvesting, and seed production of grasses require an assessment of developmental stage. A system for describing and quantifying the morphological development of a broad spectrum of perennial forage grasses is needed for making and communicating objective measurements relative to their growth and development.

A number of systems for characterizing morphological development of grasses have been described. However, they are generally intraspecific and apply to annual cereal crops (Large, 1954; Ritchie et al., 1989; Simmons et al., 1985; Vanderlip, 1979). Most of these systems were designed to be descriptive of grass morphology but provide no thorough method for quantifying development. Haun (1973) described an excellent system for quantifying wheat (Triticum aestivum L.) development. However, it applies only to
\end{abstract}

USDA-ARS and Dep. of Agron., Univ. of Nebraska, Lincoln, NE 68583. Contribution from USDA-ARS and the Nebraska Agric. Exp. Stn. Published as paper no. 9397, Journal Series, Nebraska Agric. Exp. Stn. Received 1 Oct. 1990. *Corresponding author.

Published in Agron. J. 83:1073-1077 (1991). vegetative leaf development through culm elongation and is strictly quantitative.

Simon and Park (1983) described a scheme for classifying growth stages of perennial grasses. Their system was based on that developed by Zadoks et al. (1974) for cereals with some modifications to account for developmental stages unique to perennial grasses. Although the Simon and Park (1983) system has been adopted by many researchers, it is complex and generally difficult to apply in the field.

The purpose of this research was to develop a comprehensive system for describing and quantifying the morphological development of perennial forage and range grasses. Such a system requires a universal set of morphological descriptors for forage grasses and a continuous numerical index which can be used to develop phenological and other quantitative relationships. In addition, a method for objectively applying the system to a population of grass plants or sward is required. The intent was to develop a system thorough enough for scientific purposes that could be applied routinely in the field from memory and would be useful for making practical management decisions.

\section{Description}

The system is based on five primary growth stages of individual grass shoots or tillers: (i) germination, (ii) vegetative, (iii) elongation, (iv) reproductive, and (v) seed (caryopsis) ripening (Table 1). The germination, reproductive, and seed ripening primary stages each have six secondary or substages, numbered 0 through 5, which pertain to particular events in the ontogeny of the primary shoot or tiller. The substages for these primary stages describe specific events that occur similarly in most grasses. The vegetative and elongation substages are open ended, with the number of substages being equivalent to the number of morphological events $(N)$ that occur for that species and environment.

Each individual growth stage consists of a primary and secondary stage and has both a mnemonic code and numerical index associated with it (Table 1). The codes were designed to be easily memorized and are useful for applying the system in the field. Each code

Abbreviations: MSC, mean growth stage count; $S$, growth stage; $N$, number of tillers in growth stage; $C$, total number of tillers; and $W$, dry weight for all tillers. 
Table 1. Primary and secondary growth stages and their numerical indices and descriptions for staging growth and development of perennial grasses.

\begin{tabular}{|c|c|c|}
\hline Stage & Index & Description \\
\hline \multicolumn{3}{|c|}{ Germination } \\
\hline $\begin{array}{l}\text { G0 } \\
\text { G1 } \\
\text { G2 } \\
\text { G3 } \\
\text { G4 } \\
\text { G5 }\end{array}$ & $\begin{array}{l}0.0 \\
0.1 \\
0.3 \\
0.5 \\
0.7 \\
0.9\end{array}$ & $\begin{array}{l}\text { Dry seed } \\
\text { Imbibition } \\
\text { Radicle emergence } \\
\text { Coleoptile emergence } \\
\text { Mesocotyl and/or coleoptile elongation } \\
\text { Coleoptile emergence from soil }\end{array}$ \\
\hline \multicolumn{3}{|c|}{ Vegetative-Leaf development } \\
\hline $\begin{array}{l}\text { VE or V0 } \\
\text { V1 } \\
\text { V2 } \\
\text { Vn }\end{array}$ & $\begin{array}{c}1.0 \\
(1 / N)+0.9 \dagger \\
(2 / N)+0.9 \\
(n / N)+0.9\end{array}$ & $\begin{array}{l}\text { Emergence of first leaf } \\
\text { First leaf collared } \\
\text { Second leaf collared } \\
\text { Nth leaf collared }\end{array}$ \\
\hline \multicolumn{3}{|c|}{ Elongation-Stem elongation } \\
\hline $\begin{array}{l}\text { E0 } \\
\text { E1 } \\
\text { E2 } \\
\text { En }\end{array}$ & $\begin{array}{l}2.0 \\
(1 / N)+1.9 \\
(2 / N)+1.9 \\
(n / N)+1.9\end{array}$ & $\begin{array}{l}\text { Onset of stem elongation } \\
\text { First node palpable/visible } \\
\text { Second node palpable/visible } \\
\text { Nth node palpable/visible }\end{array}$ \\
\hline \multicolumn{3}{|c|}{ Reproductive-Floral development } \\
\hline $\begin{array}{l}\text { R0 } \\
\text { R1 } \\
\text { R2 }\end{array}$ & $\begin{array}{l}3.0 \\
3.1 \\
3.3\end{array}$ & $\begin{array}{l}\text { Boot stage } \\
\text { Inflorescence emergence/1st spikelet visible } \\
\text { Spikelets fully emerged/peduncle not } \\
\text { emerged }\end{array}$ \\
\hline R3 & 3.5 & $\begin{array}{l}\text { Inflorescence emerged/peduncle fully } \\
\text { elongated }\end{array}$ \\
\hline $\begin{array}{l}\text { R4 } \\
\text { R5 }\end{array}$ & $\begin{array}{l}3.7 \\
3.9\end{array}$ & $\begin{array}{l}\text { Anther emergence/anthesis } \\
\text { Post-anthesis/fertilization }\end{array}$ \\
\hline \multicolumn{3}{|c|}{ Seed development and ripening } \\
\hline $\begin{array}{l}\text { So } \\
\text { S1 } \\
\text { S2 } \\
\text { S3 } \\
\text { S4 } \\
\text { S5 }\end{array}$ & $\begin{array}{l}4.0 \\
4.1 \\
4.3 \\
4.5 \\
4.7 \\
4.9\end{array}$ & $\begin{array}{l}\text { Caryopsis visible } \\
\text { Milk } \\
\text { Soft dough } \\
\text { Hard dough } \\
\text { Endosperm hard/physiological maturity } \\
\text { Endosperm dry/seed ripe }\end{array}$ \\
\hline
\end{tabular}

† Where $n$ equals the event number (number of leaves or nodes) and $N$ equals the number of events within the primary stage (total number of leaves or nodes developed). General formula is $\boldsymbol{P}+(n / N)-0.1$; where $\boldsymbol{P}$ equals primary stage number (1 or 2 for vegetative and elongation, respectively) and $n$ equals the event number. When $N>9$, the formula $P+0.9(n / N)$ should be used.

consists of two characters: a capital letter followed by a number. The letter denotes the primary growth stage and the number refers to the substage within that primary stage.

Numerical indices have been included so that the growth stages can be manipulated quantitatively. $\mathrm{Nu}$ merical indices for the germination, reproductive, and seed ripening stages have been arbitrarily assigned. The vegetative and elongation stage indices depend upon the number of morphological events $(N)$ occurring in that stage for the species and environment and are calculated as $P+(n / N)-0.1$; where $P$ is the primary stage number ( 1 or 2 for vegetative and elongation, respectively) and $n$ is the event number (Table 1). In the case of five events, the numerical indices for the vegetative and elongation stages are similar to those of the other primary growth stages. In cases where $N>9$, the formula $P+0.9(n / N)$ should be used to calculate the numerical index in order to achieve a value consistent with the primary growth stage.

The numerical indices are useful for calculating various statistics to describe a population of grass tillers. They also can be used as either a dependent or in- dependent variable in various mathematical models. In certain cases, the numerical indices might be modified by a researcher to better describe the relationship between a species-and-environment developmental growth response and a specific variable. However, the relationship to the actual growth stage as described by the system should be presented to prevent confusion. While the numerical index may vary somewhat between species and is subject to modification, the actual growth stages as denoted by the mnemonic codes are consistent across species and therefore unambiguous.

\section{Germination Stage}

The germination stage encompasses the events occurring after a seed is placed in the soil through coleoptile emergence from the soil (Fig. 1). Germination substages were defined on the basis of their common occurrence and order of occurrence in forage and range grasses. Other morphological events of significance during establishment of grasses, such as adventitious root development, do not occur similarly in all grasses and therefore were not included. However, in studies where the researcher is specifically interested in root development it can be described relative to germination and early vegetative growth stages.

The germination stage is unique from the other stages in that it applies to primary shoots produced from seed while each of the other stages is appropriate for both the primary shoot and tillers. For many forage grasses, once the plant is established it becomes difficult to distinguish between the primary shoot and tillers which for practical purposes become synonymous. Moreover, the primary shoot senesces with the first cycle of growth and all subsequent growth occurs from tillers (Langer, 1979).

\section{Vegetative Stage}

The vegetative stage refers to the developmental period comprising leaf growth and development (Fig. 1). The vegetative stage begins with the emergence of the first leaf from the coleoptile or prophyll in the case of tillers. Each successive substage refers to the number of fully-emerged live leaves currently present. Leaves are considered fully emerged when collared.

Only live leaves are counted because of the difficulty associated with keeping records of senesced leaves under field conditions. In certain studies, however, it may be possible and desirable to keep an accounting of senesced leaves which can be readily accomplished within the constraints of the system.

In many grasses the rate of leaf senescence is nearly equal to the rate of new leaf appearance so that the number of leaves present on a tiller becomes relatively constant once leaf senescence begins to occur (Langer, 1979). Once stem elongation commences, the elongation primary stage begins and the vegetative primary stage ceases. The appropriate value of $\mathrm{N}$ for calculating the vegetative stage numerical index is the maximum number of leaves present at any time for the species and environment prior to the initiation of stem elongation. In some cases only a small proportion of the total number of tillers will reach the highest observed vegetative stage $(N)$ before elongation begins. In this 


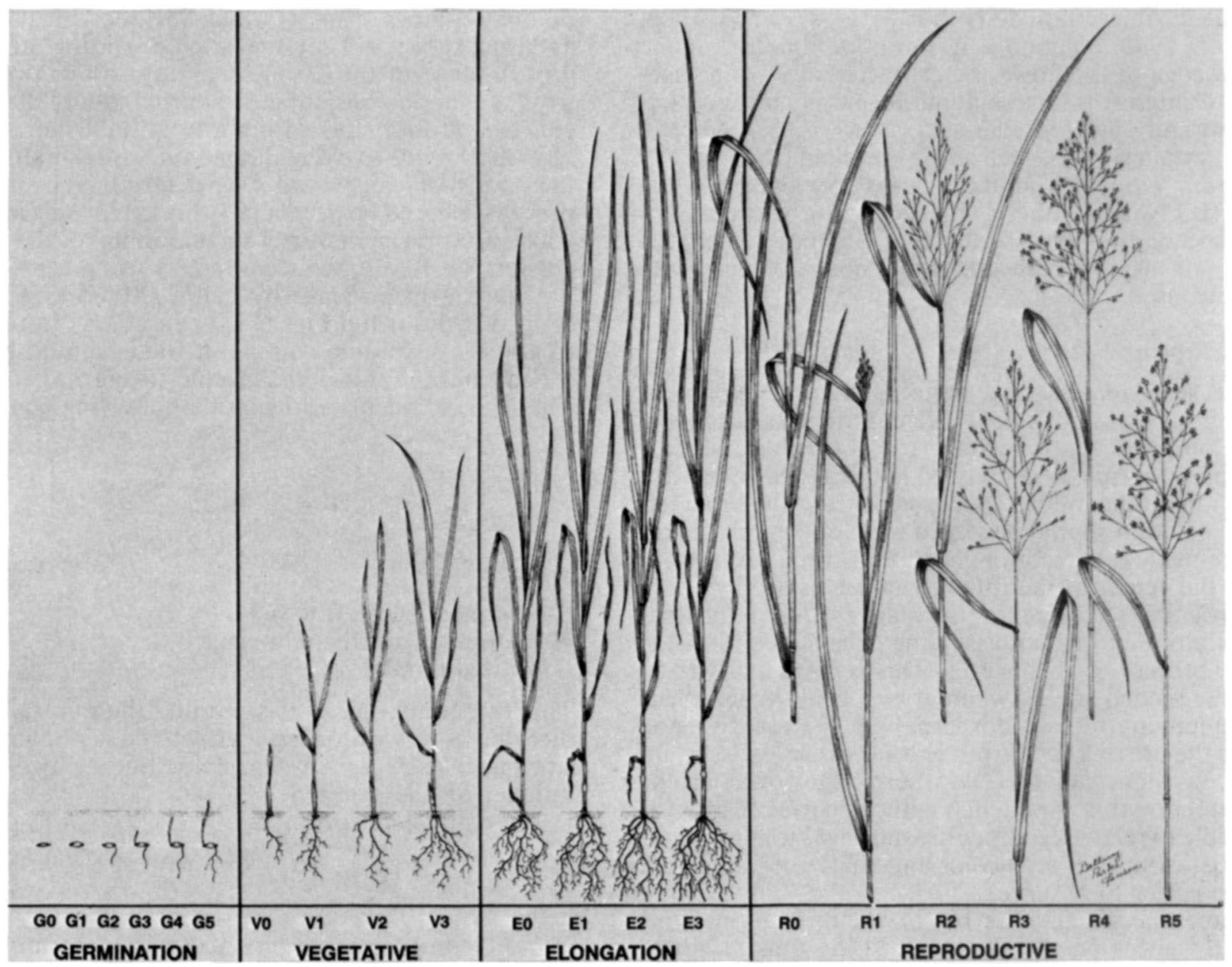

Fig. 1. Illustration of substages within the germination, vegetative, elongation, and reproductive primary growth stages. Growth stages are described in Table 1.

case the highest observed leaf number should be used to calculate the numerical index. The consequences of selecting the correct value of $N$ for the numerical index become less critical as the total number of leaves increases.

\section{Elongation Stage}

Elongation is the stage during which culm elongation occurs and is often referred to as jointing (Fig. 1). Substages of the elongation stage are defined by the number of nodes that have become either palpable or visible as the result of stem elongation.

The elongation stage ceases when the inflorescence is enclosed in the uppermost leaf sheath, which is commonly referred to as boot stage. The appropriate $\mathrm{N}$ value for calculating the numerical index is the number of nodes visible or palpable at this time. Additional nodes may become visible or palpable after this time, but they should not be included in the calculation of the numerical index.

Sterile culms are common in some perennial grass species. In the regrowth of smooth bromegrass (Bromus inermis Leyss) for example, several internodes may elongate even though the terminal meristem remains vegetative (Metcalfe and Nelson, 1985). The growth and development of sterile culms essentially becomes arrested in the highest observed elongation substage and should be staged accordingly.

\section{Reproductive Stage}

The reproductive stage begins with emergence of the inflorescence and continues through anthesis and fertilization (Fig. 1). In the Simon and Park system (1983) inflorescence emergence is described by five distinct stages based upon the proportion of the inflorescence emerged. This measurement is a subjective one since it is not generally clear what proportion of the inflorescence remains enclosed in the leaf sheath. Morphological descriptors for the reproductive substages in our system were carefully chosen to be objective.

The development of a grass inflorescence is determinate and occurs basipetally (Gould and Shaw, 1983) in most species so that spikelets borne on a single inflorescence represent a range of maturities. To assess floral development, spikelets should be evaluated at the same relative position in all inflorescences. It is recommended that spikelets approximately half way between the lower-most spikelet and apex of the inflorescence be staged. Anthesis can occur over several days for a single inflorescence and in many species 
occurs during certain daily time periods (Hovin, 1980; Burson, 1980). Therefore, it is important to have some knowledge of the flowering characteristics of the species of interest to assess floral development in a consistent and objective manner.

In certain species, such as big bluestem (Andropogon gerardii Vitman) and indiangrass [Sorghastrum nutans (L.) Nash], anthesis $\left(\mathbf{R}_{4}\right)$ can occur before the inflorescence is fully exserted $\left(R_{3}\right)$. In these cases, the early substage is skipped and the most advanced substage is used.

\section{Seed Ripening Stage}

The seed ripening stage pertains to the development of the caryopsis (Table 1). It commences when the developing caryopsis becomes readily visible and ceases when it is ripe. Because seed maturity will vary with position on the inflorescence, seeds from the same relative position should be staged from one inflorescence to the next. It is recommended that seeds taken from near the center of the inflorescence be staged.

Assigning seed ripening substages requires substantially more effort than assigning substages within the other primary growth stages. This is particularly so in smaller seeded grasses where it is difficult to detect the development of the endosperm by palpation. In many cases the use of a needle probe is necessary to ascertain the consistency of the endosperm. However, as the researcher gains experience with a species it often is possible to relate seed ripening substages to other characteristics such as seed color and shattering which are much easier to observe.

Some species such as big bluestem bear multiple inflorescences on the same culm. The most accurate method for staging a tiller bearing multiple inflorescences is to stage each individual inflorescence and calculate the mean stage for the tiller. Two alternative methods are to stage either the terminal inflorescence or the inflorescence most advanced in maturity.

\section{Application}

As noted by Simon and Park (1983), there is much variation in morphological development within cross-

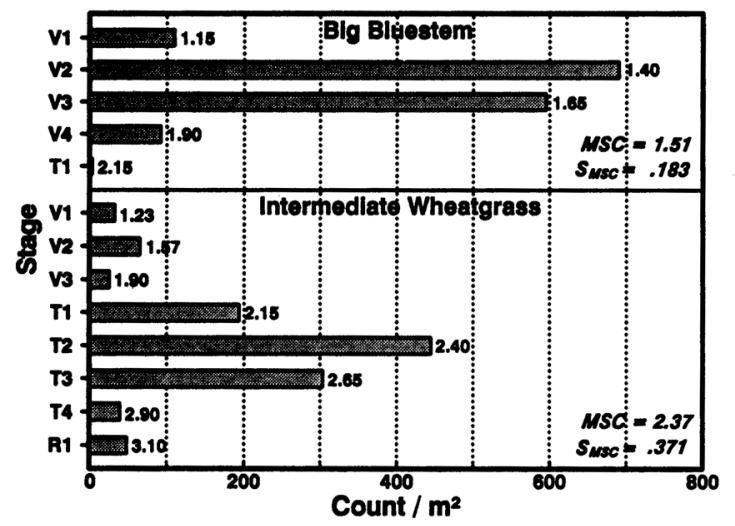

Fig. 2. Frequency distribution of growth stages, mean stage count (MSC) and the standard deviation of mean stage $\left(S_{\mathrm{MSC}}\right)$ for tillers collected from intermediate wheatgrass and big bluestem in midJune near Mead, NE. Growth stages are described in Table 1. Numbers adjacent to each bar are the numerical index for that stage. pollinated grass species, which includes most forage and range grasses. They suggested obtaining the mean growth stage of the 20 most mature tillers obtained from a sample consisting of approximately 80 tillers collected at four sites within a location. Their system obviously tends to overestimate the actual maturity of the stand. A mean growth stage determined using their procedure could be particularly biased for species with wide variation in maturity such as many of the native grasses. Therefore, we recommend using a modification of the mean stage by count (MSC) system described by Kalu and Fick (1981) for alfalfa. In the case of grasses, a random sample of tillers should be collected from the sward and grouped according to stage. The MSC is calculated using the following equation:

$$
\mathrm{MSC}=\frac{\sum_{\mathrm{i}=0}^{4.9} \sum_{\mathrm{j}=1}^{N_{\mathrm{i}}} S_{\mathrm{ij}}}{C}
$$

Where:

$S_{\mathrm{i}}=$ growth stage, 0 to 4.9

$N_{\mathrm{i}}=$ number of tillers in stage $S_{\mathrm{i}}$

$C=$ total number of tillers

This essentially involves summing the numerical indices for tillers within each growth stage, totaling the sums from each growth stage, and dividing by the total number of tillers staged.

The equivalent formula:

$$
\mathrm{MSC}=\sum_{\mathrm{i}=0}^{4.9} \frac{S_{\mathrm{i}} \times N_{\mathrm{i}}}{C}
$$

is more commonly presented and is more useful for making the actual calculations. However, it incorrectly implies that the MSC is the sum of a product. Equation [2], therefore, should be considered a working formula and Eq. [1] the appropriate definition formula.

The standard deviation of the mean stage by count $\left(S_{\mathrm{MSC}}\right)$ is an estimate of the variation about the MSC and can be calculated using the following formula:

$$
S_{\mathrm{MSC}}=\sqrt{\sum_{\mathrm{i}=0}^{4.9} \frac{\left(S_{\mathrm{i}}-\mathrm{MSC}\right)^{2} \times N_{\mathrm{i}}}{C}}
$$

The $S_{\text {MSC }}$ is useful for interpreting the variability in maturity that exists within a grass stand. A small $S_{\text {MSC }}$ indicates that most of the tillers within the stand are of similar maturity and would be expected to have a maturity near the MSC. A large $S_{\mathrm{MSC}}$ indicates that there is a wide range in maturity within the stand. It should be noted that the in order for the $S_{\text {MSC }}$ to be useful for making comparisons it must be assumed that any error associated with assigning growth stages is negligible and homogeneous among treatments.

An example of these calculations for intermediate wheatgrass [Thinopyron intermedium (Host) Barkw. \& D.R. Dewey] and big bluestem are presented in Fig. 2. Both grasses were harvested on 13 June 1990 at the University of Nebraska Agricultural Research and Development Center near Mead, Nebraska. Tillers were clipped from six randomly placed $0.09 \mathrm{~m}^{2}$ quadrats for each species. Intermediate wheatgrass, a cool-sea- 
son grass, was more mature at this particular date than big bluestem, a warm-season grass. The $S_{\mathrm{MSC}}$ for intermediate wheatgrass was approximately double that of big bluestem reflecting the wider range of maturities present in the wheatgrass. As can be seen from these data, the MSC and $S_{\mathrm{MSC}}$ together present a rather clear picture of the morphological development of the stands.

The value of estimating the mean stage from a random population of tillers is obvious when compared to other methods. In the Simon and Park (1983) method for example, the maturity of intermediate wheatgrass would have been calculated as being between the fifth node palpable and flag leaf emergence (Code $=$ 36); a stage which does not actually exist for the species. Maturity of big bluestem would have been calculated as having three leaves collared (Code $=13$ ). These estimates are biased and overestimate the maturity of the stand. The bias is particularly large in cases where the $S_{\mathrm{MSC}}$ is large as in this example with intermediate wheatgrass.

Mean growth stage also can be determined on a weight basis and in some cases may be more meaningful than MSC (Kalu and Fick, 1981). Mean stage by weight (MSW) can be calculated using Eq. [2] by replacing $N$ and $C$ with the total dry weight for the tillers in each stage $(D)$ and total dry weight for all tillers $(W)$, respectively. Because tillers accumulate more dry matter as they mature, the MSW gives more weight or leverage to tillers at advanced maturities. The MSW therefore accounts for the contribution of each growth stage to sward biomass. In the example above, the MSW for intermediate wheatgrass was calculated to be 2.58 and the MSW for big bluestem was 1.57. Calculation of the standard deviation of a MSW is not straight-forward since it is a function of a product of two variables $(S$ and $W)$ that are not independent.

The number of tillers necessary to accurately estimate the MSC or MSW for a sward will depend on the variation in maturity for a given species/environment and can be determined for each species using statistical techniques.

\section{Summary}

A system for describing and quantifying the morphological development of perennial forage and range grasses has been presented. The system was primarily designed to be used in forage and range management studies. An attempt was made to include sufficient morphological descriptors to adequately describe the growth of most perennial forage and range grasses, but to limit the number to what could be easily applied in the field from memory. It is recognized that the system may not adequately describe the growth and development of all important forage grasses. Stoloniferous species such as bermudagrass [Cynodon dactylon (L.) Pers.] may require further elaboration to describe their growth and development (West, 1990). It is also recognized that for some research objectives the number of morphological descriptors may be insufficient to describe certain growth processes. In these cases, however, a set of tertiary substages could be developed and used in conjunction with the primary and secondary stages described by the system.

\section{Acknowledgments}

Appreciation is expressed to M.T. Schroer, J.R. Hendrickson, and D.D. Wolf for evaluating the system under field conditions and to Bellamy Parks-Jansen for illustrating the growth stages.

\section{References}

Burson, B.L. 1980. Warm-season grasses. p. 695-708. In W.R. Fehr and H.H. Hadley (ed.) Hybridization of crop plants. CSSA and ASA, Madison, WI.

Gould, F.W., and R.B. Shaw. 1983. Grass systematics, 2nd ed. Texas A\&M University Press, College Station.

Hovin, A.W. 1980. Cool-season grasses. p. 285-298. In W.R. Fehr and H.H. Hadley (ed.) Hybridization of crop plants. CSSA and ASA, Madison, WI.

Haun, J.R. 1973. Visual quantification of wheat development. Agron. J. 65:116-119.

Kalu, B.A., and G.W. Fick. 1981. Quantifying morphological development of alfalfa for studies of herbage quality. Crop Sci. 21:267-271.

Langer, R.H.M. 1979. How grasses grow, 2nd Ed. Edward Arnold (Publishers) Ltd., London.

Large, E.C. 1954. Growth stages in cereals, illustration of the Feekes scale. Plant Pathol. 3:128-129.

Metcalfe, D.S., and C.J. Nelson. 1985. The botany of grasses and legumes. p. 52-63. In M.E. Heath et al. (ed.) Forages: the science of grassland agriculture, 4th ed. Iowa State University Press, Ames, IA.

Ritchie, S.W., J.J. Hanway, and G.O. Benson. 1989. How a corn plant develops. Special Report no. 48, Cooperative Extension Service, Iowa State Univ., Ames.

Simmons, S.R. E.A. Oelke, and P.M. Anderson. 1985. Growth and development of spring wheat. Univ. of Minnesota Agric. Extension Folder AG-FO-2547.

Simon, U., and B.H. Park. 1983. A descriptive scheme for stages of development in perennial forage grasses. p. 416-418. In J.A. Smith and V.W. Hays (ed.) Proc. International Grassland Congress, 14th, Lexington, KY. 15-24 June 1981. Westview Press, Boulder, $\mathrm{CO}$.

Vanderlip, R.L. 1979. How a sorghum plant develops. Cooperative Extension Service, Kansas State Univ., Manhattan.

West, C.P. 1990. A proposed growth stage system for bermudagrass. p. 38-42. In Forages - sustaining food production and environmental quality, Proc. Am. Forage and Grassl. Conf., Blacksburg, VA. 6-9 June 1990. Am. Forage and Grasslands Council, Georgetown, TX.

Zadoks, J.C., T.T. Chang, and C.F. Konzak. 1974. A decimal code for the growth stages of cereals. Weed Res. 14:515-421. 